\title{
A comparative study of oral tapentadol with thoracic epidural analgesia versus intravenous tramadol and paracetamol combination for postoperative analgesia in off pump CABG
}

\author{
Himanshu A. Shah*, Jaishree S. B., Mrugank Bhavsar
}

Department of Anaesthesia, SBKS MI \& RC, SV, Piparia, Baroda, Gujarat, India

Received: 23 August 2013 Accepted: 3 September 2013

*Correspondence to: Dr. Himanshu A. Shah, Email: sh1311@yahoo.in

(C) 2013 Shah HA et al. This is an open-access article distributed under the terms of the Creative Commons Attribution Non-Commercial License, which permits unrestricted non-commercial use, distribution, and reproduction in any medium, provided the original work is properly cited.

\begin{abstract}
Background: Accurate management of post operative pain is quite impossible with single drug therapy approach. For this, our aim was to combine use of tapentadol tablet orally along with thoracic epidural in comparison with intravenous combined use of tramadol, paracetamol and diclofenac for postoperative analgesia in case $\mathrm{CABG}$ patients.

Methods: 60 patients of CABG (Coronary Artery Bypass Surgery) randomly and equally divided into two groups. Group TTE (Tab. Tapentadol -Thoracic Epidural, $n=30$ ) were given oral Tablet Tapentadol through NG (Nasogastric) tube at the time of shifting the patient from Operation Theatre to postoperative ward along with Tramadol through Thoracic epidural catheter. In Group TPD (Tramadol -Paracetamol -Diclofenac, $n=30$ ) were given Inj. Tramadol, Inj. Paracetamol IV at time of shifting of patient. If pain score is too high $(>4)$ then additional analgesia were given with Diclofenac only if preoperative renal and hepatic profile were normal. Patients were monitored for duration of rescue analgesia, total no. of doses of analgesics in first 72 hours, total consumption of analgesics and response to physiotherapy.

Results: Duration of need of rescue analgesia was significantly longer in TTE group $(\mathrm{p}<0.05)$ while total no. of rescue doses were significantly more in group TPD $(\mathrm{p}<0.001)$. We also observed that patients of TTE group were recovered earlier, response to chest physiotherapy was significantly better and thus reduces their total length of ICU stay $(\mathrm{p}<0.05)$.

Conclusions: Our study concludes that Tapentadol with Thoracic epidural is very much effective as a multimodal analgesia approach in controlling acute postoperative pain after CABG. Tapentadol is quite a newer drug so its usefulness for other patients and different surgeries is still to be debated.
\end{abstract}

Keywords: CABG, Tapentadol, Thoracic epidural, Tramadol, Multimodal analgesia

\section{INTRODUCTION}

The experience of pain is complex, multifaceted, and "an unpleasant sensory and emotional experience," as defined in part by the International Association for the Study of Pain. It is a personal, subjective experience that involves sensory, emotional and behavioral factors associated with actual or potential tissue injury. ${ }^{1,2}$

If an appropriate analgesic treatment is not given for postoperative pain post $\mathrm{CABG}$, various respiratory adverse effects (atelectasis, retention of secretions and pneumonia, Inhibition of cough and sputum excretion), cardiovascular side effects (hypertension and arrhythmias, ST-T changes for ischemia and infarction) and CNS side effects (aggressive behavior, agitation and postoperative psychotic trauma) may occur. ${ }^{3}$

The analgesic benefits of controlling postoperative pain are generally maximized when a multimodal strategy to facilitate the patient's convalescence is implemented (Kehlet, 1997). Pain involves multiple mechanisms that ideally require treatment using a multimodal (or 'balanced') analgesic technique (White \& Kehlet, 2010) Principles of a multimodal strategy include control of postoperative pain to allow early mobilization, reduce requirement of analgesics, early enteral nutrition, and attenuation of the perioperative stress response through the use of regional anesthetic techniques and a combination of analgesic agents (i.e., multimodal analgesia). 
Tapentadol is a novel centrally acting synthetic analgesic with opioid $\mu$-receptor agonist and norepinephrine reuptake inhibitor in a single molecule. ${ }^{4,5,6}$ It is structurally and by mechanism similar to Tramadol .It displays a dual mode of action, has mild opioid activity and possesses monoamine reuptake inhibitor activity also.

Thoracic epidural analgesia (TEA) has been advantageous in providing superior analgesia and better respiratory function in comparison to opioid based intravenous techniques in different types of cardiac surgery. ${ }^{8}$

So our aim was to compare oral Tapentadol with thoracic epidural analgesia versus intravenous Tramadol and Paracetamol combination for post operative analgesia in Triple Vessel Disease (TVD) - Off Pump Coronary Artery Bypass Graft Surgery (CABG).

\section{METHODS}

After approval from the Institutional Ethical Committee and informed written consent, this prospective randomized double blind study was carried out in our cardiac centre. 60 patients of either sex scheduled for CABG were included in our study.

Patients having contraindication to opioid dependence, blood coagulopathy, history of drug allergy and abuse, spinal deformity, history of asthma, stroke, renal or liver disorder, patients developing intraoperative complications such as hypotension leading to cardiogenic shock and patient is already taking MAO inhibitors or SSRIs and any major systemic illness were excluded from the study.

60 Patients were randomly allocated into two Groups.

In Group TTE (Tapentadol + Thoracic epidural $-\mathrm{n}=30$ ), Thoracic epidural was put in T2-T3, T3-T4 or T5-T6. Intra-operative Inj. Bupivacaine $0.25 \%, 10 \mathrm{ml}$ was given just after induction. Just before shifting, Inj. Tramadol 25 $\mathrm{mg}$ diluted in 10cc Normal saline was given through epidural along with Tablet Tapentadol $50 \mathrm{mg}$ orally via NG tube. Saphenous venous harvesting causes lots of pain in lower limbs post-operatively. Thoracic epidural is not effective to relieve this pain so to prevent that we had given Tablet Tapentadol $50 \mathrm{mg} 6$ hourly for 3 days.

In Group TPD (Tramadol, Paracetamol and Diclofenac IV $-n=30$ ), Just before shifting from OT Inj. Tramadol $1.5 \mathrm{mg} / \mathrm{kg}$, Inj. Paracetamol $15 \mathrm{mg} / \mathrm{kg}$ were given. If pain score is too high $(>4)$ once patient gets awake then additional analgesia were given with Inj. Diclofenac $1 \mathrm{mg} / \mathrm{kg}$ only if pre-operative renal and hepatic profile were normal.

Anesthesia was induced with Fentanyl, 10 micrograms $/ \mathrm{kg}$, Midazolam $0.1 \mathrm{mg} / \mathrm{kg}$ and Vecuronium $0.2 \mathrm{mg} / \mathrm{kg}$, and was maintained along with Isoflurane commenced at $1 \%$ (range 0 to $2 \%$ ). Hemodynamic measurements such as pulse rate, blood pressure, $\mathrm{SpO}_{2}$, ECG, PAP, ETCO2 were at various sequences of events throughout the surgery.

In the post-operative period, patients were monitored for the duration of $1^{\text {st }}$ dose of rescue analgesia, total no. of doses, total consumption of analgesics in first 72 hours. We had also looked for the patients well being as well their response to chest physiotherapy, mobilization and total length of cardiac recovery stay. They will be also observed for complications such as nausea, vomiting, dizziness, headache, somnolence etc.

\section{Statistical Analysis}

All data were analyzed statically using $\mathrm{T}$ - test and a value of $\mathrm{P}<0.05$ was considered significant. The data's were presented as Mean \pm SD and percentage.

\section{RESULTS}

A total of 60 patients were recruited for the study. There were no significant differences between the two groups in demographic data and duration of surgery (Table 1). Hemodynamic parameters were comparable in both the groups $(\mathrm{p}>0.05)$.

Table 1: Demographic profile.

\begin{tabular}{|lllll|}
\hline Parameters & $\begin{array}{l}\text { Group } \\
\text { TTE } \\
\text { N=30 }\end{array}$ & $\begin{array}{l}\text { Group } \\
\text { TPD } \\
\text { N=30 }\end{array}$ & P Value & \\
\hline $\begin{array}{l}\text { Mean Age } \\
\text { (years) }\end{array}$ & $\begin{array}{l}58.6 \pm \\
11.9\end{array}$ & $\begin{array}{l}56.06 \pm \\
10.9\end{array}$ & $\mathrm{p}>0.05$ & NS \\
\hline $\begin{array}{l}\text { Mean Height } \\
\text { (cms) }\end{array}$ & $\begin{array}{l}158.53 \pm \\
2.13\end{array}$ & $\begin{array}{l}159.72 \pm \\
1.62\end{array}$ & $\mathrm{p}>0.05$ & $\mathrm{NS}$ \\
\hline $\begin{array}{l}\text { Mean Weight } \\
\text { (kg) }\end{array}$ & $\begin{array}{l}68.53 \pm \\
4.76\end{array}$ & $\begin{array}{l}65.56 \pm \\
3.76\end{array}$ & $\mathrm{p}>0.05$ & $\mathrm{NS}$ \\
\hline Sex (m/f) & $16 / 14$ & $17 / 13$ & & \\
\hline $\begin{array}{l}\text { Duration of } \\
\text { surgery (min) }\end{array}$ & $\begin{array}{l}198.6 \pm \\
27.2\end{array}$ & $\begin{array}{l}192.4 \pm \\
23.4\end{array}$ & $\mathrm{p}>0.05$ & $\mathrm{NS}$ \\
\hline
\end{tabular}

NS - Non Significant, S- Significant

Table 2: Analgesic profile.

\begin{tabular}{|llll|}
\hline $\begin{array}{l}\text { Analgesic } \\
\text { Profile }\end{array}$ & $\begin{array}{l}\text { Group } \\
\text { TTE }\end{array}$ & $\begin{array}{l}\text { Group } \\
\text { TPD }\end{array}$ & $\begin{array}{l}\text { P } \\
\text { value }\end{array}$ \\
\hline $\begin{array}{l}\text { Time to rescue } \\
\text { analgesia }(\text { min })\end{array}$ & $492.7 \pm 23.6$ & $\begin{array}{l}368.3 \pm \\
19.6\end{array}$ & $\begin{array}{l}\mathrm{P}< \\
0.05\end{array}$ \\
\hline $\begin{array}{l}\text { Mean no. of } \\
\text { doses per day }\end{array}$ & $3.0 \pm 0.7$ & $4.8 \pm 0.6$ & $\begin{array}{l}\mathrm{P}< \\
0.05\end{array}$ \\
\hline $\begin{array}{l}\text { Average Total } \\
\text { consumption of } \\
\text { analgesics }(\mathrm{mg})\end{array}$ & $\begin{array}{l}\text { Tramadol } \approx \\
75\end{array}$ & $\begin{array}{l}\text { Tramadol } \approx 300 \\
\text { Paracetamol } \approx\end{array}$ & \\
\hline
\end{tabular}

$\mathrm{P}<0.05$ - Significant, $\mathrm{P}>0.05-$ Non Significant 
Table 2 demonstrates analgesic profile of both the group post-operative. Since the last dose given nearly before extubation, time to rescue analgesia was observed which is significantly higher in Group TTE $(p<0.05)$. So the mean no. of total analgesic doses in first 24 hours was significantly less in Group TTE $(\mathrm{p}<0.05)$. We have also calculated average total consumption of analgesics in both the groups which was also significantly lower in Group TTE $(\mathrm{p}<0.05)$.

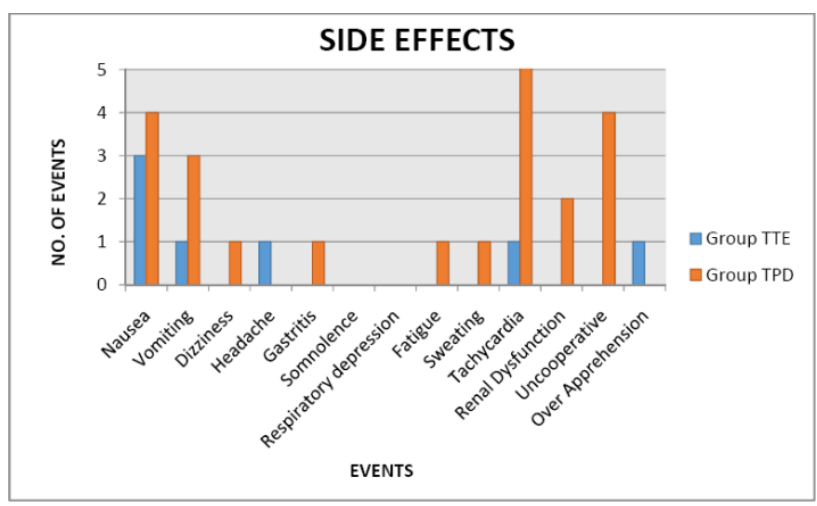

Figure 1: Side effect profile.

Figure 1 demonstrates number of different types of side effects or complications in both the groups of patient. It shows that incidence of nausea is quite high in both the groups. Even incidence of vomiting was also very high in TPD group which is significant $(\mathrm{P}<0.05)$. We have even observed significant tachycardia followed by intravenous administration of Tramadol in 17/30 cases which is quite significant. We needed to administer Diclofenac in 5 patients out of which 2 patients had increased Serum Creatinine level which is significant as well. We had seen quite a number of patients were uncooperative with intravenous Tramadol. One patient had become very apprehensive after oral Tapentadol which is significant as well. Rest of the events incidence rate was comparable in both the groups.

Table 3: Patient parameters.

\begin{tabular}{|llll|}
\hline Patient Parameters & $\begin{array}{l}\text { Group } \\
\text { TTE }\end{array}$ & $\begin{array}{l}\text { Group } \\
\text { TPD }\end{array}$ & P value \\
\hline $\begin{array}{l}\text { Chest Drainage } \\
\text { Removal (time since } \\
\text { extubation) }\end{array}$ & $\begin{array}{l}26.7 \pm \\
2.4\end{array}$ & $\begin{array}{l}31.6 \pm \\
3.7\end{array}$ & $\mathrm{P}<0.05$ \\
\hline $\begin{array}{l}\text { Time of Mobilization } \\
\text { (in hours since } \\
\text { extubation) }\end{array}$ & $\begin{array}{l}42.9 \pm \\
9.42\end{array}$ & $\begin{array}{l}58.1 \pm \\
8.76\end{array}$ & $\mathrm{P}<0.05$ \\
\hline $\begin{array}{l}\text { Total length of } \\
\text { Cardiac recovery } \\
\text { stay (in hours since } \\
\text { shifted) }\end{array}$ & $\begin{array}{l}82.9 \pm \\
9.6\end{array}$ & $\begin{array}{l}96.4 \pm \\
10.9\end{array}$ & $\mathrm{P}<0.05$ \\
\hline
\end{tabular}

$\mathrm{P}<0.05-$ Significant, $\mathrm{P}>0.05-$ Non Significant
Table 3 demonstrates other important patient parameters which is very much of clinical significance in our study. In group TTE, patients' response to inspiratory chest physiotherapy was very significant. Even chest drainage removal was earlier as compare to TPD group mainly due to better analgesia. Time of mobilization and total length of cardiac recovery stay was also comparable in both the groups.

\section{DISCUSSION}

Although guidelines have been developed to improve acute pain management, ${ }^{9,10}$ pain relief remains suboptimal for many patients. ${ }^{11-16}$ Surveys conducted among patients who had undergone ambulatory surgery indicated that $30 \%{ }^{15}$ to $40 \%{ }^{12}$ of patients experience moderate to severe pain following discharge.

A 2004 survey of patients undergoing major abdominal surgery found that many patients were willing to sacrifice pain relief for a reduction in the severity of side effects. ${ }^{17}$

The concept of multimodal analgesia was introduced more than a decade ago as a technique to improve analgesia and reduce the incidence of opioid-related adverse events (Buvanendran \& Kroin 2009). A multimodal analgesic regimen should be adjusted to meet the needs of the individual patient by taking into consideration their pre-existing medical conditions, types of surgery, and previous experiences related to both acute and chronic pain management. Several multimodal approaches have been advocated based on different combinations of anti-inflammatory drugs, and regional anesthesia (epidural, peripheral nerve blocks, paravertebral blocks, and local injection/infusion of local anesthetics) (Buvanendran, 2010; Mathiesen, 2009).

Royse $\mathrm{CF}$ et $\mathrm{al}^{18}$ demonstrated that general anesthesia combined with thoracic epidural anesthesia, allowing immediate extubation and longer duration of post-operative analgesia in patients undergoing cardiac surgeries. In our study, postoperative pain relief was superior and cardiac recovery stay was shorter in the TTE group compared to other group as well. This has been shown already in previous clinical studies. ${ }^{19}$ A cumulative meta-analysis confirmed that postoperative epidural pain control can significantly decrease the incidence of pulmonary morbidity. ${ }^{20}$ Thus, in our study patients of Group TTE had responded very well to chest physiotherapy.

In case of TVD, SVG harvesting was done from the lower limb. Thoracic epidural analgesia is very much effective around the surgical site but it had no effect on lower limb so to provide adequate pain relief over lower limb we have included Tablet Tapentadol in our study. ${ }^{19}$

Tapentadol is a novel centrally acting synthetic analgesic with $\mu$-opioid receptor agonist and norepinephrine reuptake inhibition in a single molecule. ${ }^{5,6}$ It is 14 times more efficacious than Tramadol and two times less to 
morphine. ${ }^{21,22}$ Tapentadol immediate release tablets have been approved by the FDA in 2008 for the relief of moderate to severe acute pain in adults and in 2011, for chronic pain in an extended release form. ${ }^{23}$

In all 4 phase 3 studies of Tapentadol for acute pain, improvements in pain intensity were observed with Tapentadol treatment ( $50 \mathrm{mg}$ every 4 to 6 hours). The analgesic effects of Tapentadol are independent of metabolic activation, and Tapentadol has no active metabolites. $^{24,25}$

Tapentadol and Oxycodone both have similar effect in terms on analgesia but Tapentadol has better gastric tolerability. ${ }^{26}$ In all Phase 3 trials the most commonly reported treatment emergent adverse events were typical of drugs with $\mu$-opioid agonist activity, and those were nausea, vomiting, dizziness, headache and somnolence. ${ }^{27}$ ${ }^{30}$ These are considered the most undesirable side effects associated with opioids leads to its discontinuation. ${ }^{31}$

In our study, group TTE patients had longer duration for rescue analgesia that is mainly because of the combination effects of thoracic epidural and Tapentadol. Because of prompt and sustained analgesia with Thoracic epidural and Tapentadol, patients of group TTE had greater response to chest physiotherapy, less pain score while coughing. So chest drainage was removed earlier and early mobilization started which is quite significant as compare to IV analgesic (TPD) group patients. Because of this, patients had significantly less duration of cardiac recovery stay as well.

We have also observed tachycardia in more than $50 \%$ of TPD group patients. It is commonly associated with intravenous Tramadol. $^{32}$ Diclofenac is commonly associated with renal dysfunction and it should be avoided with pre-existing deranges renal function. ${ }^{33}$ Due to inadequate analgesia we needed to administer Diclofenac in 5 patients out of which $2(40 \%)$ had developed renal dysfunction with raised Serum Creatinine. This finding has remained consistent with previous studies as well.

\section{CONCLUSION}

Our study concludes that Tapentadol with Thoracic epidural is very much effective as a Multimodal analgesia approach in controlling acute postoperative pain after CABG. It reduces requirements of opioids and thus provides good compliance to the patients in terms of early mobilization and reduces length of hospital stay. As Tapentadol is quite a newer and novel drug, other benefits and drawbacks still need to be looked for in future as well.

\section{ACKNOWLEDGEMENTS}

We are thankful to cardiothoracic surgeons and residents working with us. We are also thankful to the medical records department of our hospital.
Funding: None

Conflict of interest: None declared

Ethical approval: The study was approved by the Institutional Ethical Committee

\section{REFERENCES}

1. American Pain Society Quality of Care Committee. Quality improvement guidelines for the treatment of acute pain and cancer pain. JAMA 1995;274:187480 .

2. American Society of Anesthesiologists Task Force on Acute Pain Management. Practice guidelines for acute pain management in the perioperative setting. An updated report by the American Society of Anesthesiologists task force on acute pain management. Anesthesiology 2004;100:1573-81.

3. Apfelbaum J, Chen C,Mehta S, Gan T (2003). Postoperative pain experience: results from a national survey suggest postoperative pain continues to be undermanaged. Anesth Analg, Vol.97, No.2 (Aug), pp.534-40.

4. Thomas Christoph, Babette Kögel, Tapentadol HCl: a Novel ì-Opioid Receptor Agonist/Nor epinephrine Reuptake Inhibitor with Broad-Spectrum Analgesic Properties, Journal of Pharmacology \& Experimental Therapeutics, vol.323,no.1265-276, 2007.

5. Tzschentke TM, Christoph T, Kögel B, et al. (-)(1R,2R)-3- (3-Dimethylamino-1-ethyl-2-methylpropyl)-phenol hydrochloride (tapentadol $\mathrm{HCl}$ ): a novel $\mu$ opioid receptor agonist/norepinephrine reuptake inhibitor with broad-spectrum analgesic properties. J Phar- macol Exp Ther. 2007;323(1): 265-276.

6. Tzschentke TM, De Vry J, Terlinden R, et al. Tapentadol HCl. Drugs Future. 2006;31(12):10531061.

7. Two New Analgesics May Help Patients After Bunionectomy". Journal of Anaesthesiology Clinical Pharmacology. September 26, 2006.

8. Liu S, Carpenter RL, Neal JM. Epidural anesthesia and analgesia. Their role in postoperative outcome. Anesthesiology 1995; 82: 1474-506.

9. American Society of Anesthesiologists Task Force on Acute Pain Man- agement. Practice guidelines for acute pain management in the periop- erative setting. A report by the American Society of Anesthesiologists Task Force on Pain Management, Acute Pain Section. Anesthesiology. 1995;82(4): 1071-1081.

10. American Society of Anesthesiologists Task Force on Acute Pain Management. Practice guidelines for acute pain management in the perioperative setting: an updated report by the American Society of Anesthesiologists Task Force on Acute Pain Management. Anesthesiology. 2004;100(6):15731581.

11. Apfelbaum JL, Chen C, Mehta SS, Gan TJ. Postoperative pain experience: results from a national 
survey suggest postoperative pain continues to be undermanaged. Anesth Analg. 2003;97(2): 534-540.

12. Beauregard L, Pomp A, Choiniere M. Severity and impact of pain after day-surgery. Can J Anaesth. 1998;45(4):304-311.

13. Carroll KC, Atkins PJ, Herold GR, et al. Pain assessment and manage- ment in critically ill postoperative and trauma patients: a multisite study. Am J Crit Care. 1999;8(2):105-117.

14. Dix P, Sandhar B, Murdoch J, MacIntyre PA. Pain on medical wards in a district general hospital. $\mathrm{Br} \mathrm{J}$ Anaesth. 2004;92(2):235-237.

15. McGrath B, Elgendy H, Chung F, Kamming D, Curti B, King S. Thirty percent of patients have moderate to severe pain $24 \mathrm{hr}$ after ambulatory surgery: a survey of 5,703 patients. Can J Anaesth. 2004;51(9):886-891.

16. McNeill JA, Sherwood GD, Starck PL, Thompson CJ. Assessing clinical outcomes: patient satisfaction with pain management. J Pain Symptom Manage. 1998;16(1):29-40.

17. Gan TJ, Lubarsky DA, Flood EM, et al. Patient preferences for acute pain treatment. Br J Anaesth. 2004;92(5):681-688.

18. Royse CF, Royse AG, Soeding PF. Routine immediate extu- bation after cardiac operation: a review of our first 100 patients. Ann Thorac Surg 1999;68:1326-9.

19. Blomberg S, Emanuelsson H, Ricksten S. Thoracic epidural an- esthesia and central hemodynamics in patients with unstable angina pectoris. Anesth Analg 1989;69:558-62.

20. Ballantyne JC, Carr DB, de Ferranti S, et al. The comparative effects of postoperative analgesic therapies on pulmonary outcome: cumulative metaanalyses of randomized, controlled trials. Anesth Analg 1998;86:598-612.

21. Regina Kleinert, Claudia Lange, , Achim Steup, Single Dose Analgesic Efficacy of Tapentadol in Postsurgical Dental Pain: The Results of a Randomized, Double-Blind, Placebo-Controlled Study, Journal of Anesthesia \& Analgesia, December 2008 vol. 107 no. 6 2048- 2055.

22. Tschentke, T.M. et al. "Tapentadol Hydrochloride." Drugs of the Future. 2006, Vol. 31, Issue 12, p. 1053. DOI: $10.1358 /$ dof.2006.031.12.1047744.

23. Cepeda, M. Soledad MD, PhD*; Sutton, Alex PhD†; Weinstein, Rachel PhD*; Kim, Myoung PhD, Effect of Tapentadol Extended Release on Productivity: Results From an Analysis Combining Evidence From Multiple Sources-In Clinical Journal of Pain: January 2012 - Volume 28 - Issue 1 - p 8-13.

24. Terlinden R, Kögel B, Englberger W, Tzschentke T. In vitro and in vivo characterization of tapentadol metabolites. Methods Find Exp Clin Pharmacol. 2010;32:31-8.

25. Stephen E. Daniels, and Michael Golf. Clinical Efficacy and Safety of Tapentadol Immediate Release in the Postoperative Setting. J Am Podiatr Med Assoc 2012;102(2):139-48.

26. Kleinert, R; Lange, C; Steup, A; Black, P; Goldberg, J; Dejardins, P. "Single Dose Analgesic Efficacy of Tapentadol in Postsurgical Dental Pain: The Results of a Randomized, Double-Blind, Placebo-Controlled Study". International Anesthesia Research Society Vol. 107, No. 6, December 2008.

27. Daniels S, Casson E, Stegmann JU, et al. A randomized, double-blind, placebo-controlled phase 3 study of the relative efficacy and tolerability of tapentadol IR and oxycodone IR for acute pain. Curr Med Res Opin. 2009;25(6):1551-1561.

28. Daniels SE, Upmalis D, Okamoto A, Lange C, Haeussler J. A random- ized, double-blind, phase III study comparing multiple doses of tapent- adol IR, oxycodone IR, and placebo for postoperative (bunionectomy) pain. Curr Med Res Opin. 2009;25(3):765-776.

29. Hartrick C, Van Hove I, Stegmann JU, Oh C, Upmalis D. Efficacy and tolerability of tapentadol immediate release and oxycodone $\mathrm{HCl}$ immediate release in patients awaiting primary joint replacement surgery for end-stage joint disease: a 10-day, phase III, randomized, double-blind, activeand placebo-controlled study. Clin Ther. 2009;31(2):260-271.

30. Hale M, Upmalis D, Okamoto A, Lange C, Rauschkolb C. Tolerability of tapentadol immediate release in patients with lower back pain or osteoarthritis of the hip or knee over 90 days: a randomized, double- blind study. Curr Med Res Opin. 2009;25(5):1095-1104.

31. Nicholson B. Responsible prescribing of opioids for the management of chronic pain. Drugs. 2003;63(1):17-32.

32. Henry A. Spiller, Susan E. Gorman, Danny Villalobos, Blaine E. Benson Prospective Multicenter Evaluation of Tramadol Exposure. 1997, Vol. 35, No. 4 , Pages 361-364.

33. Pérez Gutthann S, García Rodríguez LA, Raiford DS, Duque Oliart A, Ris Romeu J. Nonsteroidal Anti-inflammatory Drugs and the Risk of Hospitalization for Acute Renal Failure. Arch Intern Med. 1996;156(21):2433-2439.

doi:10.5455/2319-2003.ijbcp20131210

Cite this article as: Shah HA, SB Jaishree, Bhavsar

M. A comparative study of oral tapentadol with thoracic epidural analgesia versus intravenous tramadol and paracetamol combination for postoperative analgesia in off pump CABG. Int $\mathbf{J}$ Basic Clin Pharmacol 2013;2:723-7. 